\title{
Evaluation of preventative and control measures for congenital syphilis in State of Mato Grosso
}

\author{
Leila Regina de Oliveira ${ }^{[1]}$, Maria da Conceição Nascimento Costa ${ }^{[2]}$, \\ Florisneide Rodrigues Barreto ${ }^{[2]}$, Susan Martins Pereira ${ }^{[2]}$, Inês Dourado ${ }^{[2]}$ \\ and Maria Glória Teixeira ${ }^{[2]}$
}

[1]. Instituto de Ciências da Saúde, Universidade Federal de Mato Grosso, Campo Grande, MS. [2]. Instituto de Saúde Coletiva, Universidade Federal da Bahia, Salvador, BA.

\begin{abstract}
Introduction: Congenital syphilis is an important health problem in Brazil. This study assessed measures aimed at the prevention and control of syphilis in the State of Mato Grosso and its capital, Cuiabá. Methods: A descriptive study cross-sectional and of time trends assessing the congenital syphilis was performed in Cuiabá and Mato Grosso between 2001 and 2011. We compared maternal sociodemographic characteristics and health care utilization related to cases of congenital syphilis during the periods from 2001 to 2006 and from 2007 to 2011. We assessed the temporal trends in this disease's incidence using a simple linear regression. Results: Between 2001 and 2006 in Mato Grosso, 86.8\% of the mothers who had live births with congenital syphilis received prenatal care, $90.6 \%$ presented with a nontreponemal test reagent at delivery, $96.2 \%$ had no information regarding a treponemal confirmatory test at delivery, and $77.6 \%$ received inadequate treatment for syphilis; additionally, $75.8 \%$ of their partners were not treated. There was a statistically significant reduction in prenatal visits $(p=0.004)$ and an increase in the proportion of mothers reactive to nontreponemal tests at delivery $(p=0.031)$ between the two periods. No other variables were found to differ significantly between the periods. In Cuiabá, we observed a similar distribution of variables. In the state and in the capital, the increasing trend of congenital syphilis was not statistically significant. Conclusions: The high incidence of congenital syphilis in Mato Grosso and the low levels of health care indicators for pregnant women with syphilis suggest the need to improve the coverage and quality of prenatal care.
\end{abstract}

Keywords: Congenital syphilis. Health evaluation. Prenatal care.

\section{INTRODUCTION}

Gestational syphilis is a major cause of adverse pregnancy outcomes, including spontaneous abortion, perinatal death, prematurity, low birth weight, and other problems ${ }^{1-3}$. Estimations indicate that from 2008 to 2009, seropositivity for syphilis among pregnant women who attended prenatal consultations ranged from $0.06 \%$ in the Mediterranean region to $2.13 \%$ in Africa, and approximately 1.4 million pregnant women worldwide are infected with Treponema pallidum ${ }^{4}$. This scenario is indicative of a high incidence of congenital syphilis, which might be asymptomatic or show mild or nonspecific symptoms; alternatively, congenital syphilis might present as a syndrome with various clinical manifestations such as massive sepsis, bone lesions, and cutaneous-mucous and central nervous system lesions. This syndrome could lead to death ${ }^{5}$.

\footnotetext{
Address to: Dra ${ }^{\mathrm{a}}$ Maria Glória Teixeira. ISC/UFBA. Rua Basílio da Gama s/n, Canela, 40110-040 Salvador, BA, Brasil.

Phone: 5571 3283-7445

e-mail: magloria@ufba.br

Received 6 February 2014

Accepted 18 June 2014
}

Although some countries, such as Canada, the United States, Chile, and Cuba, already show rates compatible with the elimination of congenital syphilis, in the Americas, between 164,000 and 344,000 children continue to be born with this infection annually, which demonstrates that syphilis continues to be an important public health problem in the region ${ }^{6}$. In Brazil, 14,321 cases of syphilis were reported in pregnant women in 2011; the detection rate was 5.0 in 1,000 live births (LBs), and the incidence rate of congenital syphilis in infants $<1$ year old was 3.3 in 1,000 $\mathrm{LBs}^{7}$.

The high incidence of syphilis in pregnant women highlights the problems with women's healthcare; this high incidence suggests that basic care for these patients, such as the diagnosis and treatment of sexually transmitted diseases, is being neglected. The occurrence of congenital syphilis is an indicator of poor quality prenatal care, indicating that there are structural and operational weaknesses in health services ${ }^{8}$. Although there are effective and low-cost measures for preventing and controlling this disease, there are behavioral and sociocultural issues that hinder the adoption of such measures, thus contributing to a reduction in the effectiveness of these measures.

With a view toward encouraging countries in the Americas to incorporate strategies aimed at coping with the problem of congenital syphilis into their agendas, the Pan American Health Organization (PAHO) recommended the adoption of a plan to 
reduce the vertical transmission of syphilis in $1995^{9}$. In 2005, this organization proposed the goal of reducing the incidence of congenital syphilis, including stillbirths, to a maximum of 0.5 cases per $1,000 \mathrm{LBs}$ by the year $2015^{10}$. In line with these initiatives and to strengthen the Health Pact created in $2006^{11}$, Brazil proposed guidelines for congenital syphilis control that same year ${ }^{12}$ and the Operational Plan to reduce the vertical transmission of syphilis in the following year ${ }^{13}$. This plan includes increased coverage of syphilis screening during prenatal care, adequate treatment of infected pregnant women and their sexual partners, and actions aimed at the prevention of vertical transmission of syphilis in exposed pregnant women and children.

In view of the importance of health assessments in guiding the processes of implementation, consolidation and reshaping of public policies, programs, and public health practices, and considering the need to reduce the vertical transmission of syphilis, it is important to verify that the actions that have been adopted in Brazil for the control of this problem are producing the expected results. Thus, this study aims to evaluate the preventative and control measures for the transmission of syphilis that have been 'developed in the State of Mato Grosso and its capital, Cuiabá.

\section{METHODS}

This is a descriptive study cross-sectional and of time trend that examines confirmed cases of congenital syphilis in LBs from mothers living in the State of Mato Grosso and in Cuiabá between 2001 and 2011 .

\section{Data sources}

Data on cases of syphilis were taken from the Notifiable Diseases Information System (SINAN/DATASUS - Sistema Nacional de Agravos de Notificação/Departamento de Informática do Sistema Único de Saúde), from the databases from the State Secretariat of Health of Mato Grosso, and from the Municipal Secretariat of Health of Cuiabá. Epidemiological Investigation Datasheets were used for cases of gestational syphilis and congenital syphilis. Data on the number of LBs and on the number of deaths caused by congenital syphilis were obtained from the Live Birth Information System (SINASC - Sistema de Informações sobre Nascidos Vivos) and the Mortality Information System (Sistema de Informações sobre Mortalidade - SIM).

\section{Cross-sectional analysis}

Because gestational syphilis became a compulsorily notifiable condition in $2005^{15}$, cases of congenital syphilis were aggregated for the periods 2001-2006 and 2007-2011 to ascertain if there had been changes in the maternal sociodemographic characteristics (i.e., age, education, and race/ skin color) or in health care (i.e., diagnosis of infection during prenatal care, management of prenatal care, nontreponemal test at delivery, treponemal confirmatory test at delivery, maternal and partner treatment, and vertical transmission of syphilis). The percentages of each variable were calculated; cases with missing information and cases not registered were excluded from the analysis. To assess differences in the proportions between the two periods, Pearson's chi-squared test and, when indicated, Fisher's exact test were used.

The rate of vertical transmission of syphilis was analyzed beginning in 2007 because information from the first two years after the mandatory reporting of cases of this disease in pregnant women was unreliable.

\section{Time trend analysis}

A time series was constructed from the annual incidence rates of congenital syphilis, and its magnitude and fluctuations were described. We evaluated the temporal trend of the series via a simple linear regression analysis using a significance level of 0.05 . The calendar year (i.e., independent variable) was centralized to avoid autocorrelation among the regression terms. The statistical analyses were performed using Stata software (Data Analysis and Statistical Software; StataCorp; Texas, USA; Version 12).

\section{Ethical considerations}

The Ethics Committee for Research of the Institute of Public Health of the Federal University of Bahia (CEP/ISC/UFBA Comitê de Ética em Pesquisa do Instituto de Saúde Coletiva da Universidade Federal da Bahia) approved the study design (registration Number 40/12).

\section{RESULTS}

Between 2001 and 2011, 567 cases of congenital syphilis were reported in Mato Grosso, of which 525 (92.6\%) cases were confirmed. The majority of the mothers of LBs with syphilis in the 2001-2006 period were between 20 and 34 years old (73.2\%) and had $4-7$ or $8-11$ years of education $(42.3 \%$ and $35.8 \%$, respectively); $47.9 \%$ of these mothers were mixed race, and $40.7 \%$ were white. During the period from 2007 to 2011, the distribution of these characteristics remained similar. When comparing the two periods with respect to education and race/skin color, both variables were statistically significant $(p<0.001)$. Cuiabá contributed $230(40.6 \%)$ cases to the total number of cases reported in the state; 225 (97.8\%) of these cases were confirmed. In the capital city, during the earlier period, the highest percentages were found in mothers aged 20-34 $(69.9 \%)$ and $<20$ years $(23.3 \%)$, in those with $8-11$ years of education $(53.3 \%)$, and in mixed race women $(59.7 \%)$. The same patterns were observed in all of the variables except race/skin color in the 2007-2011 period; this variable showed a reduction in the proportion of white women and an increase in black women. This was the only variable that exhibited a statistically significant difference $(p=0.038)$ between the periods. The percentage of unrecorded information was $>37 \%$ for race/skin color and 40\% for education in both periods (Table 1).

As shown in Table 2, in Mato Grosso, during the first period of the study, $86.8 \%$ of the mothers of LBs with congenital syphilis received prenatal care. Of these mothers of LBs with 
congenital syphilis, $90.6 \%$ were reactive to the nontreponemal test reagent at delivery, $96.2 \%$ had no recorded information regarding receiving a treponemal confirmatory test at delivery, $77.6 \%$ received treatment that was considered inadequate, and $75.8 \%$ had partners who were not treated. Between 2007 and $2011,75.6 \%$ of the mothers received prenatal care, $50.3 \%$ received a prenatal diagnosis of maternal syphilis, $95.9 \%$ exhibited reactivity to the nontreponemal test reagent, $58.2 \%$ did not undergo a confirmatory treponemal test at delivery, $78.2 \%$ received inadequate treatment, and $77.2 \%$ did not have partners who were treated concurrently. In $>37 \%$ of the cases from both analyzed periods, there was no record of the variable of the treatment of partners. A statistically significant difference in the distribution of the variables between time periods was only observed in the proportion of mothers who underwent prenatal visits $(p=0.004)$ and in the proportion of those who were reactive to the nontreponemal test at delivery $(p=0.031)$.
Table 2 indicates that in Cuiabá, between 2001 and 2006, $81.8 \%$ of the mothers of LBs with congenital syphilis received prenatal care, and $91.2 \%$ were reactive to a nontreponemal test at delivery; the maternal treatment scheme was inadequate in $80.6 \%$ of the cases, and in $76.8 \%$, the partner was not treated. In the later period, $25.6 \%$ of women did not receive prenatal care and $43.3 \%$ were found to have syphilis at delivery. At delivery, $96 \%$ and $66.7 \%$ showed reactivity to the nontreponemal test and to the confirmatory treponemal test, respectively. For the majority of the analyzed variables, the proportion of entries with missing data ranged from $15 \%$ to $28.6 \%$. The differences observed between the two periods were not statistically significant and were borderline $(\mathrm{p}=0.055)$ for partner treatment.

From 2007 to 2011 in Mato Grosso, the frequency of vertical transmission of syphilis was $24.6 \%$ (average). In Cuiabá, the rate of vertical transmission of syphilis ranged from $100 \%$ in 2009 to $36.8 \%$ in 2011 (Table 3). Among the detected cases of

TABLE 1 - Number and percentage of detected cases* of congenital syphilis stratified by maternal sociodemographic characteristics. State of Mato Grosso and Cuiabá, 2001-2011.

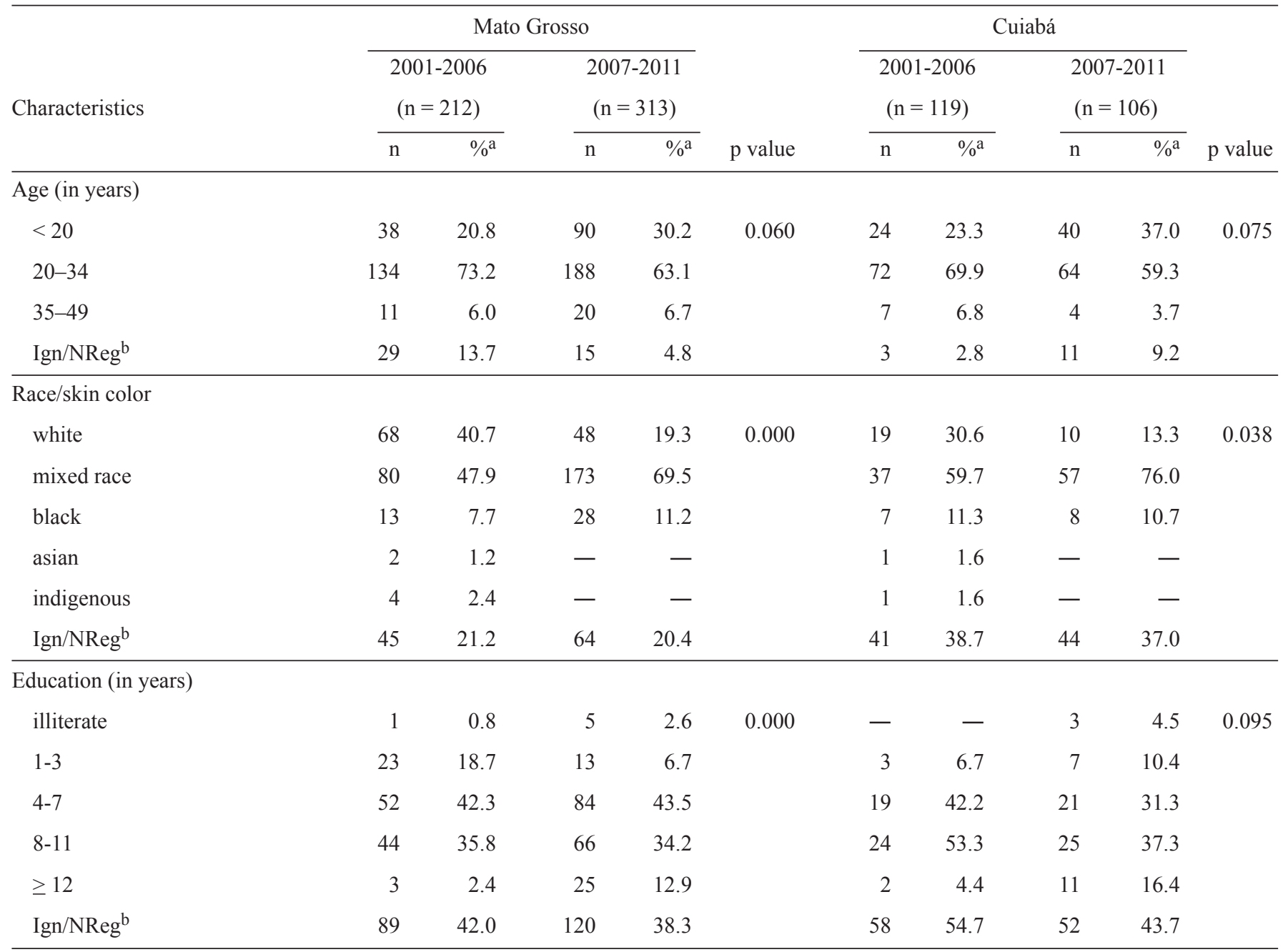

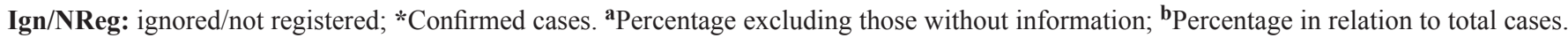
Source: Brazilian Case Registry Database (Sistema de Informação de Agravos de Notificação - SINAN); Epidemiological Research Forms; State Secretariat of Mato Grosso and Cuiabá Municipal Secretariat Databases. 
TABLE 2 - Number and percentage of detected cases* of congenital syphilis stratified by variables relating to maternal health care. State of Mato Grosso and Cuiabá, 2001-2006 and 2007-2011.

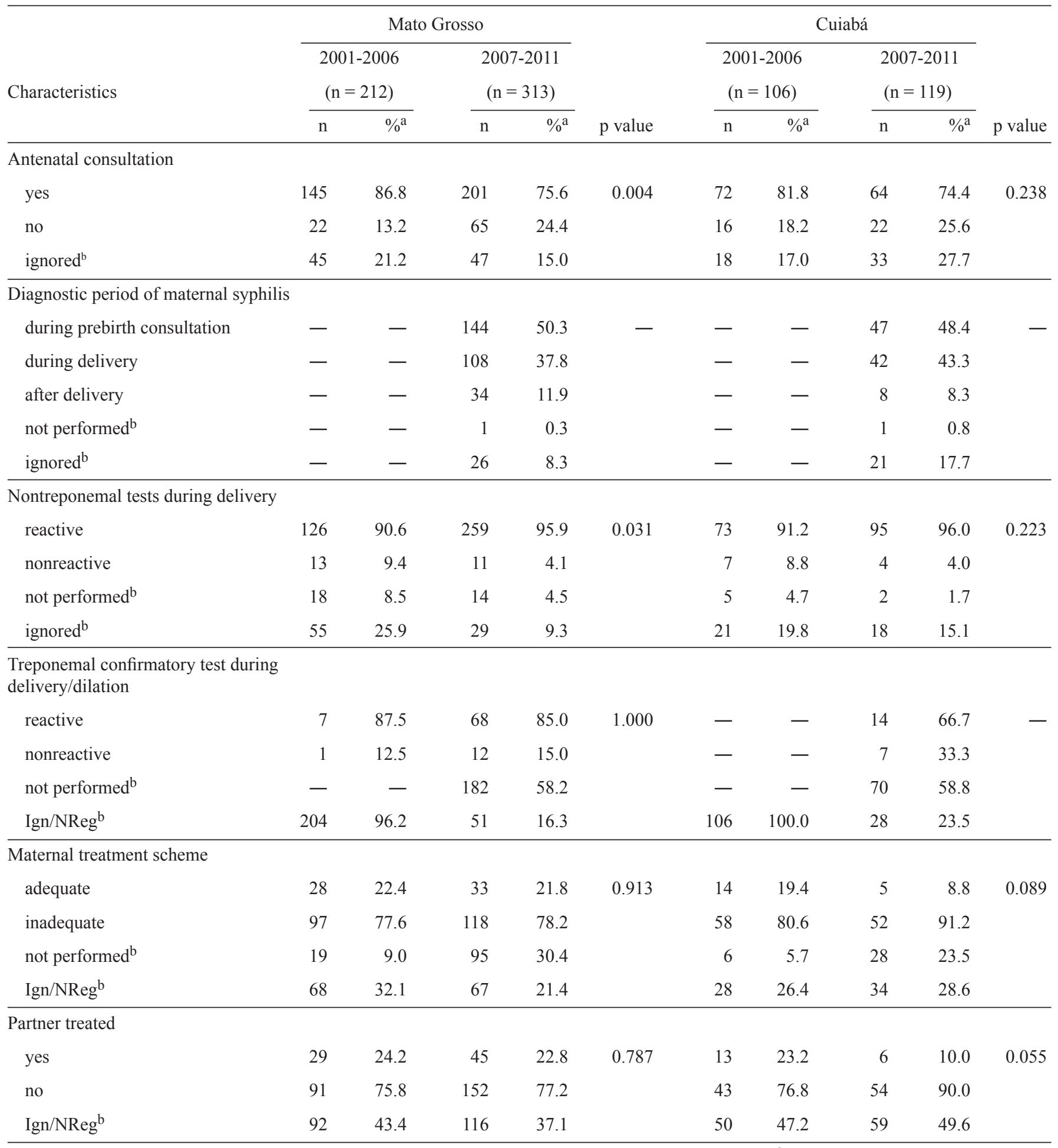

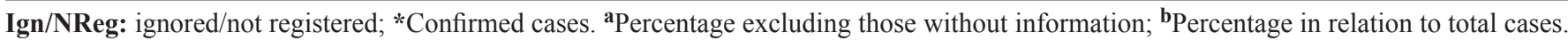
Source: Brazilian Case Registry Database (Sistema de Informação de Agravos de Notificação - SINAN); Epidemiological Research forms; State Secretariat of Mato Grosso and Cuiabá Municipal Secretariat Databases. 
TABLE 3 - Number of cases of gestational syphilis and congenital syphilis (in infants $<1$ year old) and the rate of vertical transmission of syphilis*. State of Mato Grosso and Cuiabá, 2007-2011.

\begin{tabular}{|c|c|c|c|c|c|c|}
\hline \multirow[b]{2}{*}{ Year } & \multicolumn{3}{|c|}{ Mato Grosso } & \multicolumn{3}{|c|}{ Cuiabá } \\
\hline & syphilis & (< 1 year $)$ & of syphilis $(\%)$ & syphilis & (< 1 year $)$ & of syphilis (\%) \\
\hline 2007 & 132 & 39 & 29.6 & 25 & 21 & 84.0 \\
\hline 2008 & 159 & 41 & 25.8 & 31 & 22 & 71.0 \\
\hline 2010 & 256 & 64 & 25.0 & 54 & 20 & 37.0 \\
\hline 2011 & 275 & 59 & 21.5 & 38 & 14 & 36.8 \\
\hline
\end{tabular}

*Ratio of newborns with congenital syphilis in comparison with the total number of pregnant women with syphilis. Source: Brazilian Case Registry Database (Sistema de Informação de Agravos de Notificação - SINAN); State Secretariat of Mato Grosso and Cuiabá Municipal Secretariat Databases.

congenital syphilis, the proportions classified as recent were $70.7 \%$ and $70 \%$ in Mato Grosso and $96.1 \%$ and $91.1 \%$ in Cuiabá during the first and second periods, respectively.

The incidence coefficients of congenital syphilis ranged from 0.35 in 1,000 LBs in 2004 to 1.66 in 1,000 LBs in 2010 in the State of Mato Grosso and from 0.54 in 1,000 LBs in 2004 to 4.06 in 1,000 LBs in 2006 in Cuiabá (Figure 1). In Mato Grosso $(\beta=0.114, p=0.06)$ and in Cuiabá $(\beta=0.027, p=0.925)$, the growth trend of congenital syphilis was not statistically significant. The fatality rate for this disease in the state was $15.4 \%$ in 2007 and $5.1 \%$ in 2011 ; in the capital city, the fatality rate was $9.5 \%$ and $7.1 \%$ in 2007 and 2011, respectively.

\section{DISCUSSION}

The high frequency of pregnant women infected with T. pallidum who were not diagnosed while receiving prenatal care in Mato Grosso between 2001 and 2011 and the high frequency of women who had a laboratory diagnosis of this disease only at birth and who received inappropriate treatment or no treatment at all are important pieces of evidence indicating failures in the process of care for pregnant women by the health services network in this state. It is known that even at birth, serological screening is an important measure. This screening represents a new opportunity to treat pregnant women with syphilis and children with congenital syphilis who do not have clinical signs or symptoms of the infection at birth and who constitute approximately two-thirds of infected children ${ }^{12}$. Thus, these findings indicate that several opportunities were missed to diagnose and treat a disease that could cause various adverse outcomes for pregnant women, as well as prevent congenital syphilis, a disease that has serious consequences for the fetus.

Although the coverage of antenatal consultations among these pregnant women with syphilis was greater than $70 \%$, this value cannot be considered to be satisfactory because the ideal should be close to $100 \%$. Moreover, this indicator decreased during the period analyzed and does not reveal the number of

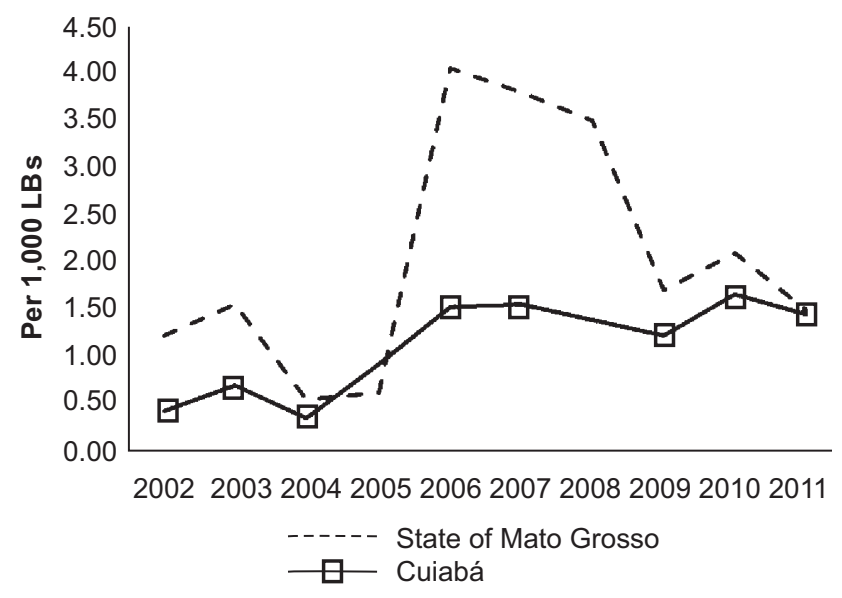

FIGURE 1 - Incidence (per 1,000 LBs) of congenital syphilis in children $<1$ year of age according to the place of residence and year of occurrence. State of Mato Grosso (MT) and Cuiabá, 2002-2011. Source: Brazilian Case Registry Database (Sistema de Informação de Agravos de Notificação - SINAN); State Secretariat of Mato Grosso and Cuiabá Municipal Secretariat Databases. LBs: live births.

antenatal consultations nor whether these consultations took place during the period recommended by the protocol of the Brazilian Ministry of Health ${ }^{16}$. According to data from the SINASC in the State of Mato Grosso, fewer than $65 \%$ of live births in the period from 2007 to 2011 were from mothers who received seven or more antenatal consultations ${ }^{17}$. The average coverage of the Family Health Strategy in 2009 and 2010 was $45.7 \%$, whereas the target coverage was approximately $66.3 \%{ }^{18}$. Therefore, these data suggest the possibility that the results found in this study might apply to the entire pregnant population of that state.

In Mato Grosso, the increase during the later study period in live births with congenital syphilis whose mothers were 
under 20 years could not be attributed to better record keeping because the proportion of women with no recorded age increased in Cuiabá. If these results are real, this growth might indicate that adolescents are more vulnerable to pregnancy and sexually transmitted disease at early ages. The association between teenage mothers and congenital syphilis ${ }^{18}$ strengthens this hypothesis.

In accordance with the results of previous investigations ${ }^{19,20}$, more black and brown women were diagnosed with gestational syphilis in Mato Grosso. This finding might reflect the racial composition of the population of that state because, in the 2010 Census, more than $65 \%$ of the population was reported as having this skin color $^{21}$. The finding could also be due to the low economic status of the black population in the country. However, the high rate of underreporting of this variable demands caution in interpreting this finding. The low educational level observed for most pregnant women with syphilis in this study and in other studies ${ }^{19,20}$ also indicates that these women are from disadvantaged populations.

The marked temporal variation in the incidence of congenital syphilis throughout the study suggests the existence of underreporting, which is also noted in other municipalities ${ }^{22,23}$; the underreporting might be compounded by the difficulty of determining a clinical diagnosis of this disease in newborns. It is noteworthy that underreporting of health information could be considered to be an indirect indicator of poor quality of health care. The high incidence of congenital syphilis, coupled with the magnitude of the risk of vertical transmission of this infection, which was higher than the target of less than 1/1,000 LBs proposed by Ministry of Health ${ }^{12}$, suggests that the efforts being undertaken by the Unified Health System (SUS - Sistema Único de Saúde) for the improvement of primary health care have been insufficient to achieve the desired effect on the occurrence of this disease.

This scenario for congenital syphilis in Mato Grosso is also found in other areas of Brazil $1^{19,20,24,25}$. A national survey conducted in this country revealed a high (1.7\%) prevalence of positive serology for syphilis in a random sample of postpartum women in the maternity reference index from the sexually transmitted disease/acquired immunodeficiency syndrome (STD/AIDS) National Program. The index also revealed that only $43 \%$ of these women received six or more prenatal visits, and 3\% underwent the recommended diagnostic and therapeutic procedures to prevent the vertical transmission of syphilis.

Therefore, it is understood that, despite the poor quality of secondary data and the fact that the analyzed indicators were only for pregnant women with syphilis, these findings are evidence of possible weaknesses in the quality of prenatal care in Mato Grosso. This situation emphasizes the importance of immediate interventions aimed at addressing this problem by health managers. These initiatives should include expanding the coverage of care provided; better training of human resources involved in prenatal care, especially with regard to prevention of the vertical transmission of syphilis and health promotion and prevention activities; and improving the organization of health services, in particular with regard to facilitating the flow of all phases of medical management from the request for laboratory tests to the receipt of the results in a timely manner to proceed with appropriate treatment.

In this process, health service professionals and users of health services must be made aware of the benefits of fully adopting and implementing the simple and effective procedures that should be provided to pregnant women.

\section{CONFLICT OF INTEREST}

The authors declare that there is no conflict of interest.

\section{REFERENCES}

1. De Santis M, De Luca C, Mappa I, Spagnuolo T, Licameli A, Straface $\mathrm{G}$, et al. Syphilis infection during pregnancy: fetal risks and clinical management. Infect Dis Obstet Gynecol 2012; 1:1-5.

2. Sauteur PMM, Trück J, Bosshard PP, Tomaske M, Cadenas FM, Lautenschlager S, et al. Congenital syphilis in Switzerland: gone, forgotten, on the return. Swiss Med Wkly 2012; 141:1-6.

3. Nascimento MI, Cunha AA, Guimarães EV, Alvarez SS, Oliveira SSSM, Villas Boas EL. Gestações complicadas por sífilis materna e óbito fetal. Rev Bras Ginecol Obstet 2012; 34:56-62.

4. Newman L, Kamb M, Hawkes S, Gomez G, Say L, Seuc A, et al. Global estimates of syphilis in pregnancy and associated adverse outcomes: analysis of multinational antenatal surveillance data. PLoS Med 2013; 10:e1001396.

5. Haroon S, Velaphi S, Goga Y, Afadapa N, Steen R, Lincetto O. The prevention and management of congenital syphilis: an overview and recommendations. Bull World Health Org 2004; 82:424-430.

6. Organização Pan-Americana de Saúde (OPAS). Organização Mundial da Saúde (OMS). Escritório Regional para as Américas. Panorama Regional e Perfis de Países. Edição de 2012. Publicação Científica e Técnica No. 636; Washington, DC: OPAS, 2012. [Cited 2013 August 17]. Available from: http://apsredes.org/site2012/wp-content/uploads/2012/09/Sa\%C3\%BAde-nasAm\%C3\%A9ricas3.pdf/.

7. Ministério da Saúde, Secretaria de Vigilância em Saúde, Departamento de DST, Aids e Hepatites Virais. Boletim Epidemiológico - Sífilis. Ano 1, nº 01. [Cited 2013 September 11]. Brasília: Ministério da Saúde. Available from: http://www.aids.gov.br/sites/default/files/anexos/publicacao/2012/52537/ boletim_sifilis_2012_pdf_26676.pdf/.

8. Ministério da Saúde. Secretaria de Vigilância em Saúde. Programa Nacional de DST e Aids. Plano Operacional para redução da transmissão vertical do HIV e da Sífilis no Brasil. Brasília: Ministério da Saúde; 2007.

9. Organización Panamericana de la Salud (OPAS). Organización Mundial de la Salud (OMS). Eliminación de la Sífilis Congénita en las Américas; 1995. [Cited 2013 November 9]. Available from: http://hist.library.paho. org/Spanish/GOV/CD/20775.pdf.

10. Organização Panamericana de Saúde. Plano Regional para HIV/AIDS e DST 2006-2015. CSP28/INF/3 (Port.), p. 20-26; 2005. [Cited 2012 October 16]. Available from: http://www.paho.org/english/ad/fch/ai/ HIV_Regional_Plan_2006-2015_english.pdf

11. Ministério da Saúde. Portaria no 399/GM DE 22 de fevereiro de 2006. Divulga o Pacto pela Saúde 2006-Consolidação do SUS e aprova as Diretrizes Operacionais do referido Pacto. 2006; 1-23. [Cited 2012 October 14]. Available from: http://bvsms.saude.gov.br/bvs/publicacoes/ prtgm399_20060222.pdf/.

12. Ministério da Saúde. Secretaria de Vigilância em Saúde. Programa Nacional de DST/AIDS. Diretrizes para controle da Sífilis Congênita: manual de bolso. Série Manuais 24. $2^{\text {nd }}$. ed. Brasília: Ministério da Saúde; 2006. 
13. Ministério da Saúde. Secretaria de Vigilância em Saúde. Programa Nacional de DST e Aids. Plano Operacional para redução da transmissão vertical do HIV e da sífilis no Brasil. Brasília: Ministério da Saúde; 2007.

14. Felisberto E. Da teoria à formulação de uma Política Nacional de Avaliação em Saúde: reabrindo o debate. Ciênc Saude Colet 2006; 11:553-563.

15. Ministério da Saúde. Secretaria de Vigilância em Saúde. Portaria nº 33 , de 14 de julho de 2005. Inclui doenças à relação de notificação compulsória, define agravos de notificação imediata e a relação dos resultados laboratoriais que devem ser notificados pelos laboratórios de referência nacional ou regional. Diário Oficial da União, Brasília, Seção 1. p.111, 15 jul. 2005.

16. Ministério da Saúde. Programa de Humanização do Parto. Humanização do pré-natal e nascimento. PHPN 2000. Brasília: Ministério da Saúde; 2000; [Cited 2012 October 14]. Available from: http://bvsms.saude.gov. br/bvs/publicacoes/parto.pdf/.

17. Ministério da Saúde. Departamento de Informática do SUS-DATASUS. Sistema de Informação sobre Nascidos Vivos/SINASC. [Cited 2013 November 8]. Available from: http://www2.datasus.gov.br/DATASUS/ index.php?area $=0205 \& \mathrm{VObj}=\mathrm{http}: / /$ tabnet.datasus.gov.br/cgi/deftohtm. exe? sinasc/cnv/nv/.

18. Secretaria de Estado de Saúde de Mato Grosso. Superintendência de Atenção à Saúde. Indicadores da Atenção Primária: situação de indicadores prioritários da atenção básica nos municípios de Mato Grosso de 2006 a 2010. Cuiabá: Secretaria de Estado de Saúde de Mato Grosso; 2012.
19. Araújo MAL, Freitas SCR, Moura HJ, Gondim APS, Silva RM. Prevalence and factors associated with syphilis in parturient women in Northeast, Brazil. BMC Public Health 2013; 13:206.

20. Melo NGDO, Melo Filho DA, Ferreira LOC. Diferenciais intraurbanos de sífilis congênita no Recife, Pernambuco, Brasil (2004-2006). Epidemiol Serv Saúde 2011; 20:213-222.

21. Instituto Brasileiro de Geografia e Estatística (IBGE). Censo 2010. Rio de Janeiro: IBGE. [Cited 2013 November 6]. Available from: http:// censo2010.ibge.gov.br/resultados/.

22. Saraceni V, Vellozo V, Leal MC, Hartz ZMA. Estudo de confiabilidade do SINAN a partir das Campanhas para a Eliminação da Sífilis Congênita no Município do Rio de Janeiro. Rev Bras Epidemiol 2005; 8:419-424.

23. Magalhães DMS, Kawaguchi IAL, Dias A, Calderon IMP. Sífilis materna e congênita: ainda um desafio. Cad Saude Publica 2013; 29:1109-1120.

24. Campos ALA, Araujo MAL, Melo SP, Gonçalves MLC. Epidemiologia da sífilis gestacional em Fortaleza, Ceará, Brasil: um agravo sem controle. Cad Saude Publica 2010; 26:1747-1755.

25. Domingues RMSM, Saraceni V, Hartz ZMA, Leal MC. Congenital syphilis: a sentinel event in antenatal care quality. Rev Saude Publica 2013; 47:147-157.

26. Rodrigues CS, Guimarães MDC. Grupo Nacional de Estudo sobre Sífilis Congênita. Positividade para Sífilis em puérperas: ainda um desafio para o Brasil. Rev Panam Salud Publica 2004; 16:168-175. 